\title{
Assessment of the length of sick leave in patients with ischemic heart disease
}

\author{
Nausica Català Tella ${ }^{1 *}$, Catalina Serna Arnaiz ${ }^{1}$, Jordi Real Gatius ${ }^{2,3}$, Oriol Yuguero Torres ${ }^{4}$ \\ and Leonardo Galván Santiago ${ }^{5}$
}

\begin{abstract}
Background: The prevalence of ischemic heart disease is high. Few recent studies have investigated the periods of sick leave of these patients. Our aim is to determine the length of sick leave after an acute coronary syndrome, its costs, associated factors and to assess the use of antidepressants and/or anxiolytics.

Methods: An observational study of a retrospective cohort of patients on sick leave due to ischemic heart disease in a health region between 2008-2011, with follow-up until the first return to work, death, or end of the study (31/12/2012). Measurements: length of sick leave, sociodemographic variables and medical prescriptions.

Results: Four hundred and ninety-seven patients (mean age 53 years, 90.7\% male), diagnosed with acute myocardial infarction (60\%), angina pectoris (20.7\%) or chronic form of ischemic heart disease (19.1\%). Thirty-seven per cent of patients took anxiolytics the year after diagnosis and 15\% took antidepressants. The average duration of sick leave was 177 days (95\% Cl: 163-191 days). Patients diagnosed with acute myocardial infarction returned to work after a mean of 192 days, compared to 128 days in cases with angina pectoris. Patients who took antidepressants during the year after diagnosis returned to work after a mean of 240 days. The mean work productivity loss was estimated to be 9,673 euros/person.
\end{abstract}

Conclusions: The mean duration of sick leave due to ischemic heart disease was almost six months. Consumption of psychotropic medication doubled after the event. Older age, suffering an acute myocardial infarction and taking antidepressants were associated with a longer sick leave period.

Keywords: Sick leave, Ischemic heart disease, Acute coronary syndrome, Coronary heart disease, Acute myocardial ischemia, Cost, Anxiety/depression

\section{Background}

In recent decades, mortality rates after Ischemic Heart Disease (IHD) have declined in developed countries, but IHD nonetheless remains the leading cause of death in men and the second most frequent in women [1]. A study in the primary care setting places the prevalence of IHD in the general population over 15 years at $5.5 \%$ [1]. The mortality rate of patients with Acute Coronary Syndrome (ACS) in the first month is $50 \%$; almost half of these deaths occur in the first two hours, mainly due to ventricular fibrillation [2]. This high prehospital

\footnotetext{
* Correspondence: ncatala@hotmail.com

${ }^{1}$ ABS Eixample, Institut Català de la Salut, Balmes avenue, 4, 25006 Lleida,

Spain

Full list of author information is available at the end of the article
}

mortality has not changed in recent years, although hospital mortality has decreased notably [2].

It is estimated that every year cardiovascular disease causes over 4 million deaths in Europe as a whole, and 1.9 million deaths in the European Union, most due to Coronary Heart Disease [3]. From an epidemiological point of view, IHD is particularly important in our environment due to its high prevalence, the high consumption of resources it requires, and the associated mortality. The increase in its prevalence and advances in technology have established IHD as the disease with the greatest economic impact in the developed countries [4]. Incapacity for work is one of the indirect costs of the disease, but this issue has not been widely studied [4-6]. Few authors have assessed the length of periods of sick leave due to IHD $[2,7-10]$ since the review of the topic conducted in 
2004 by Perk and Alexanderson [11]. The study by Sicras-Mainar in 2009 quantified the cost per patient following an episode of ACS at 14,069 euros (87\% of which were direct costs and 13\% lost productivity costs). The direct costs comprised primary care (20\%) and specialized care (67\%), with hospitalization costs accounting for $63 \%$ of the total [5].

Advances in the management of the acute phase of ACS and of heart failure and revascularization in angina pectoris, among other conditions, have improved prognosis and recovery time. These developments may potentially allow a much earlier return to work.

Incapacity for work is one of the major contributing factors to the economic burden of a disease. If current healthcare systems are to remain viable, clinicians, economists, health authorities and the biomedical industry must work together to establish a consensus on issues such assustainable periods of sick leave indifferent clinical situations [4].

The present study was designed to determine the mean length of sick leave after an ACS. We also aimed to evaluate some of the associated factors such as age, sex, specific diagnosis andthe prescription of medicationfor depression or anxiety, and to estimate the indirect costs of incapacity for work associated with ischemic heart disease.

\section{Methods}

This observational, retrospective, longitudinal study examined data from the primary care clinical records of patients in the health region of Lleida between 1 January 2008 and 31 December 2011. Data were extracted on all patients aged between 18 and 65 years diagnosed with IHD and on sick leave taken forthis condition. Patients' evolution was followed until December 31, 2012.

\section{Data source}

The data were obtained from the medical histories in the database of the Catalan Health Service primary care section. In Catalonia, the use of the health card is mandatory to obtain medication through the Social Security system. The sedatives prescribed corresponded to the groups N03AE/N05BA-BB-BX-CD-CF-CM and the antidepressants to the groups N06A/N06B/N06C in the Anatomical Therapeutic Chemical classification used in Spain [12].

Date of birth, sex, employment, exitus (if appropriate) and diagnosis of IHD were extracted from the primary care information systems in accordance with the International Classification of Diseases-10 (ischemic heart disease: I20-I25).

\section{Variables}

The variables assessed were length of sick leave period (calculated from the beginning of the leave until the return to work, or until 31/12/2012 or date of death), age at the beginning of sick leave, sex, clinical diagnosis of IHD, and the prescription of antidepressants and/or anxiolytics.

\section{Patient selection criteria}

Patients with incapacity due to IHD recorded between 1 January 2008 and 31 December 2011, aged 18 to 65 at the time of diagnosis, and living in the Lleida health region were included.

\section{Non-healthcare costs}

Indirect costs were those relating to productivity loss (number of periods of sick leave and total days off work). They were quantified according to the minimum wage (Source: Spanish Institute of Statistics), considering the cost per day not worked at 54.65 euros [5]. Indirect costs were estimated for the whole of the patients' follow-up period.

\section{Statistical analysis}

Descriptive analysis of the general characteristics of the cohort, expressing qualitative variables as frequencies and percentages and quantitative variables as means and standard deviations (SD). The duration of sick leave was estimated by survival analysis until the return to workusing the Kaplan-Meier method. The length of periods of sick leave was compared using the Log-Rank hypothesis test. At multivariate level, Hazards ratios for return to workwere estimated from the fit of the multivariate Cox regression models. The assumption of proportional hazards of the Cox models was evaluated using Schofield residuals. Data were analysed using the IBM SPSS statistical package (version 19). The main results are expressed with 95\% confidence intervals (95\%) and $p$-values less than 0.05 were considered statistically significant.

\section{Results}

Of a total of 497 patients with incapacity due to IHD, 90.7\% were male. The most common diagnosis was acute myocardial infarction (AMI - 59.4\%), followed by angina pectoris (20.7\%) and chronic forms of IHD (19.1\%). The remaining $0.8 \%$ were due to other acute ischemic heart diseases and complications after AMI. The average age was 53 years (SD: 7.4). Broken down by years, 142 individuals were diagnosed with IHD (28.6\%) in 2008; $117(23.5 \%)$ in 2009; $112(22.5 \%)$ in 2010, and finally $126(25.4 \%)$ in 2011. Anxiolytic treatment was required by $37 \%$ of patients within 12 months of diagnosis, and antidepressant treatment by $15 \%$ (Table 1).

The estimated mean length of sick leave was 177 days (95\% CI 163-191). In women it was 152 days compared with 180 days in men, though the difference was not 
Table 1 Descriptive data of the variables analysed

\begin{tabular}{|c|c|c|}
\hline Variables & Number & Percent \\
\hline \multicolumn{3}{|l|}{ Diagnostic code (CIE10) and description } \\
\hline Angina (120) & 103 & $20.70 \%$ \\
\hline Acute myocardial infarct (AMI) (I21) & 295 & $59.40 \%$ \\
\hline Complications following AMI (I23) & 1 & $0.20 \%$ \\
\hline Other acute ischemic heart disease (I24) & 3 & $0.60 \%$ \\
\hline Chronic ischemic heart disease (125) & 95 & $19.10 \%$ \\
\hline \multicolumn{3}{|l|}{ Age group } \\
\hline$<=45$ years & 88 & $17.70 \%$ \\
\hline 46 to 55 & 195 & $39.20 \%$ \\
\hline$>=56$ & 214 & $43.10 \%$ \\
\hline \multicolumn{3}{|l|}{ Year of sick leave } \\
\hline 2008 & 142 & $28.60 \%$ \\
\hline 2009 & 117 & $23.50 \%$ \\
\hline 2010 & 112 & $22.50 \%$ \\
\hline 2011 & 126 & $25.40 \%$ \\
\hline \multicolumn{3}{|l|}{ Sex } \\
\hline Female & 48 & $9.70 \%$ \\
\hline Male & 449 & $90.30 \%$ \\
\hline \multicolumn{3}{|l|}{ Medication dispensed : Yes/No ATC code) } \\
\hline \multicolumn{3}{|l|}{ Prior sedative (N03AE N05BA-BB-BX-CD-CF-CM) } \\
\hline Previous & 136 & $27.4 \%$ \\
\hline Previous 6 months & 73 & $14.7 \%$ \\
\hline Previous 12 months & 95 & $19.1 \%$ \\
\hline Subsequent 12 months & 184 & $37.0 \%$ \\
\hline \multicolumn{3}{|l|}{ Antidepressants GT = N06A / N06B / N06C } \\
\hline Previous & 74 & $14.9 \%$ \\
\hline Previous 6 months & 30 & $6.0 \%$ \\
\hline Previous 12 months & 39 & $7.8 \%$ \\
\hline Subsequent 12 months & 76 & $15.3 \%$ \\
\hline
\end{tabular}

statistically significant $(p=0.22)$. Half of the participants were on sick leave for less than four months.

The length of the sick leave period increased with age, as the older group ( $\geq 56$ years) had a mean sick leave of 186 days ( $\approx 6$ months) compared with 140 days $(\approx 4.5$ months $)$ in the $\leq 45$ year group $(p<0.05)$ (Table 2). Patients with angina pectoris were the first to return to work (Fig. 1); on average, patients diagnosed with AMI and IHD returned to work 60 days $(p=0.002)$. Finally, patients who required antidepressant medication in the 12 months after diagnosis had longer periods of sick leave $(p<0.05)$ than those who did not (Table 2).

Table 3 shows the multivariate analysis of the hazards ratios for returning to work depending on the variables analysed. Delayed return to work was associated with the diagnosis of myocardial infarction, older age, and taking antidepressant treatment.

In 12 of the 497 cases studied, the full sick leave period was not recorded. In five cases this was because of the finalization of the study on $31 / 12 / 2012$; one patient moved to another centre, and six died.

The mean indirect cost due to loss of work productivity was estimated at 9,673 euros.

\section{Discussion}

Patients who take sick leave due to IHD are predominantly male, and more than half havediagnoses of AMI. As regards medication, more than a third of these patients take anxiolytic treatment a year after diagnosis, and $15 \%$ antidepressants. In fact, patients' consumption of anxiolytics or antidepressants doubles after the cardiovascular event. The mean period of sick leave is 177 days; the figure increases with age and in patients diagnosed with AMI. Patients receiving antidepressants have the longest mean period of sick leave (233 days).

Most patients on sick leave are male. Recent surveybased studies in the US continue to show a predominance of males in heart disease in general and in AMI in particular $[13,14]$. Among the 40-59 year age group, the prevalence is $3.3 \%$ in males and $1.8 \%$ in females [13]. No recent data are available on the prevalence of heart disease in our country, but an indirect estimation can be made using data from the population surveys carried out by the National Institute of Statistics $[13,15]$. In the last two surveys, which referred explicitly to AMI, estimates for each age group were well below those recorded in the US population, although males predominated in this country as well $(0.64 \%$ in men vs. $0.15 \%$ in women in the $45-54$ year age group $1.84 \%$ in men and $1.28 \%$ in women in the 55-64 year age group). In fact, ever since the Framingham cohort's study it has been acknowledged that the incidence of coronary events increases rapidly with age and those rates are lower in women than in men $[13,16,17]$.

Although little recent information on the length of sick leave due to IHD is available in the literature, our results are consistent with the few reports published to date. Andrée et al. [18] reported that $2.2 \%$ of applications for sick leave conceded in Spain in 2009 were due to cardiovascular disease, and that the sick leave period lasted more than six months in $69.9 \%$ of these patients. As that study did not differentiate according to type of cardiovascular event, the results cannot be compared directly with ours, since we focused specifically on ischemic heart disease. Lopez de la Iglesia reported that, in most cases of IHD, return to work is possible within 90 to 180 days [2]. Other sources like the Spanish National Social Security Institute (INSS) set the mean time for return to work after AMI at 90 days, ranging between 60 
Table 2 Estimated time in days of the overall period of sick leave according to group

\begin{tabular}{|c|c|c|c|c|c|c|c|c|}
\hline \multirow{2}{*}{ Variable } & & \multirow[b]{2}{*}{ Mean } & \multicolumn{2}{|l|}{$95 \% \mathrm{Cl}$} & \multirow[b]{2}{*}{ Median } & \multicolumn{2}{|l|}{$95 \% \mathrm{Cl}$} & \multirow{2}{*}{$\begin{array}{l}p \text {-value } \\
\text { imit) }\end{array}$} \\
\hline & & & (Upper limit - & Lower limit) & & (Upper limit - & Lower li & \\
\hline Global & & 177.3 & $(163.5-$ & 191.0) & 116 & (98.6- & 133.4) & \\
\hline \multicolumn{3}{|l|}{ Diagnostic code (CIE10) and description } & & & & & & 0.002 \\
\hline \multicolumn{2}{|l|}{ Angina (I20) } & 127.8 & (99.9- & 155.6) & 68 & $(46.6-$ & 89.4) & \\
\hline \multicolumn{2}{|l|}{ Acute Myocardial Infarction (I21) } & 191.8 & $(174.1-$ & 209.5) & 131 & $(102.1-$ & 159.9) & \\
\hline \multicolumn{2}{|l|}{ Other acute ischemic heart disease (I24) } & 143.0 & $(47.8-$ & 238.2) & 187 & $(0.0-$ & 412.6) & \\
\hline \multicolumn{2}{|l|}{ Chronic ischemic heart disease (I25) } & 187.7 & $(154.5-$ & 220.9) & 137 & $(105.7-$ & 168.3) & \\
\hline \multicolumn{2}{|l|}{ Age group (in years) } & & & & & & & 0.042 \\
\hline \multicolumn{2}{|l|}{$<=45$ years } & 139.7 & $(110.2-$ & 169.2) & 88 & $(56.7-$ & 119.3) & \\
\hline \multicolumn{2}{|l|}{46 to 55} & 184.4 & $(161.7-$ & 207.1) & 125 & $(98.4-$ & 151.6) & \\
\hline \multicolumn{2}{|l|}{$>=56$} & 186.1 & $(165.2-$ & 207.1) & 137 & $(103.4-$ & 170.6) & \\
\hline \multicolumn{2}{|l|}{ Sex } & & & & & & & 0.221 \\
\hline \multicolumn{2}{|l|}{ Female } & 152.5 & $(110.7-$ & 194.3) & 99 & $\left(62.8^{-}\right.$ & 135.2) & \\
\hline \multicolumn{2}{|l|}{ Male } & 179.9 & $(165.3-$ & 194.5) & 119 & $(101.0-$ & 137.0) & \\
\hline \multicolumn{9}{|l|}{ Previous medication } \\
\hline \multirow[t]{2}{*}{ Previous sedative (N03AE N05BA-BB-BX-CD-CF-CM) } & $\mathrm{SI}$ & 189.6 & $(162.7-$ & 216.6) & 126 & $(80.3-$ & 171.7) & 0.35 \\
\hline & No & 172.4 & $(156.5-$ & 188.4) & 112 & $(93.5-$ & 130.5) & \\
\hline \multirow[t]{2}{*}{ Sedative in previous 12 months (N03AE N05BA-BB-BX-CD-CF-CM) } & $\mathrm{Si}$ & 208.4 & $(173.8-$ & 243.0) & 160 & $(84.5-$ & 235.5) & 0.045 \\
\hline & No & 169.7 & $(154.9-$ & 184.5) & 111 & $(95.1-$ & 126.9) & \\
\hline \multirow[t]{2}{*}{ Previous antidepressants: GT = N06A/N06B/N06C } & $\mathrm{Si}$ & 181.3 & $(146.5-$ & 216.1) & 137 & $(90.2-$ & 183.8) & 0.577 \\
\hline & No & 176.5 & $(161.5-$ & 191.4) & 111 & (93.6- & 128.4) & \\
\hline \multirow[t]{2}{*}{ Antidepressants in previous 12 months : GT = N06A/N06B/N06C } & $\mathrm{Si}$ & 228.9 & $(174.0-$ & 283.8) & 191 & $(105.3-$ & 276.7) & 0.022 \\
\hline & No & 172.8 & $(158.7-$ & 186.9) & 110 & $(92.7-$ & 127.3) & \\
\hline \multicolumn{9}{|l|}{ Subsequent medication (12 months) } \\
\hline \multirow[t]{2}{*}{ Sedatives } & $\mathrm{Si}$ & 199.3 & $(175.6-$ & 223.0) & 150 & $(113.5-$ & 186.5) & 0.015 \\
\hline & No & 164.2 & $(147.5-$ & 180.9) & 103 & $(88.9-$ & 117.1) & \\
\hline \multirow[t]{2}{*}{ Antidepressants } & $\mathrm{Si}$ & 240.2 & (199.3- & 281.1) & 196 & (133.0- & 259.0) & $<0.001$ \\
\hline & No & 165.9 & (151.6- & 180.2) & 108 & (93.1- & 122.9) & \\
\hline
\end{tabular}

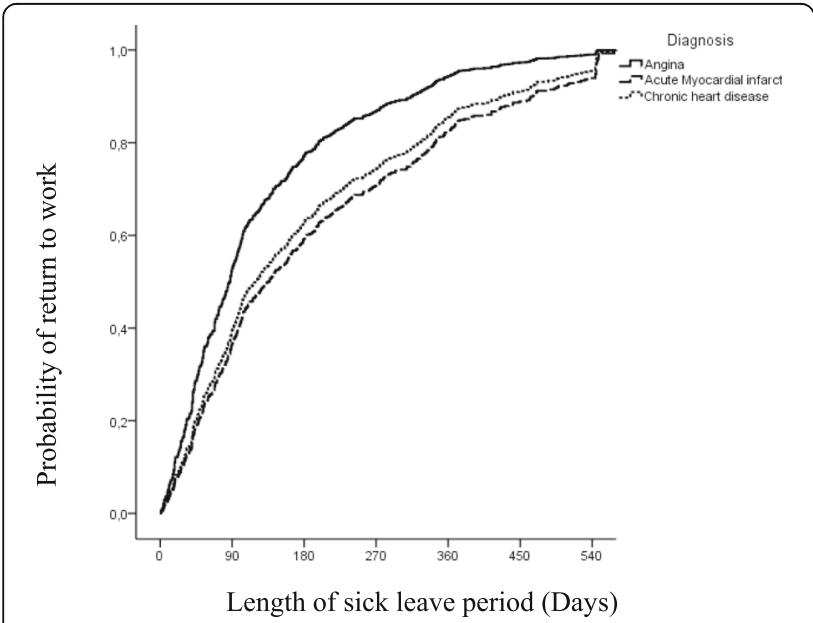

Fig. 1 Probability of return to work in relation to the length of sick leave period and 120 days depending on the anatomical location of the event and the diagnosis, with 30 days for both angina pectoris and old myocardial infarction [10]. Other studies of sick leave in the general population report longer periods and a wide variability, ranging from 189 days in the study by Jiménez [8] to 244 days in the study by Gutiérrez Morlote [9] and to a mean of 255 days in the Andalusia study protocol [7].

After an extensive review of the bibliography, Perk \& Alexanderson (2004) state that few articles of scientific quality specifically discuss the duration of sick leave due to coronary heart disease. Perk \& Alexanderson say that in Sweden a sick leave of at least three months is common after AMI [11, 19], and that in several European countries and the US the median duration of sick leave in this situation is 60 days [20]. The review concludes that there is no evidence to support the differences in the sick leave period from an international perspective 
Table 3 Estimation of Hazard Ratio (HR) of return to work in relation to the variables analysed using the Cox regression model

\begin{tabular}{|c|c|c|c|c|}
\hline \multirow{2}{*}{$\begin{array}{l}\text { Variable } \\
\text { Category }\end{array}$} & \multirow[b]{2}{*}{$H R$} & \multicolumn{2}{|l|}{$95 \% \mathrm{Cl}$} & \multirow[b]{2}{*}{$p$-value } \\
\hline & & (Lower level - & Upper level) & \\
\hline \multicolumn{5}{|l|}{ Sex } \\
\hline Female & 1.36 & $(1.00-$ & 1.86) & 0,051 \\
\hline Age in years & 0.99 & $(0.97-$ & 1.00) & 0.025 \\
\hline Diagnosis (Ref: Chronic ischemic heart disease) & & & & $<0.001$ \\
\hline Angina (CIE10:I20) & 1.49 & $(1.12-$ & 1.98) & 0.006 \\
\hline Acute myocardial infarct (CIE10:121) & 0.91 & $(0.71-$ & 1.15) & 0.421 \\
\hline \multicolumn{5}{|l|}{ Medication previous 12 month (Ref: None) } \\
\hline Sedative (N03AE N05BA-BB-BX-CD-CF-CM) & 0.88 & $(1.08-$ & $0.72)$ & 0.217 \\
\hline Antidepressants GT = N06A / N06B / N06C & 0.64 & $(0.84-$ & $0.48)$ & 0.002 \\
\hline
\end{tabular}

[11]. Factors related to the almost infinite peculiarities of job positions, considerations such as age, motivation, satisfaction with previous position, salary, trade, unemployment rates, comorbidity, or even economic aspects - which in some studies have proved more influential on return to work than clinical endpoints are involved in the decision [21-23]. Lastly, an important aspect to be considered is the timing of the return to work. Levine et al. say that traditionally, there was a wide timeframe for return to work after an acute coronary event [9, 21, 24]; however, this recommendation is now obsolete as it does not take into account the major improvements in acute therapies, preventive treatments and cardiac rehabilitation that have been achieved in recent years. Modern guidelines, though not entirely clear, have shortened this timeframe to $1-3$ months [25].

The factor associated most clearly with longer sick leave was the concomitant use of antidepressant treatment. Previous studies have demonstrated the association between ischemic heart disease and depression: patients with cardiovascular disease are twice as likely to develop depression [26], and depression increases cardiovascular mortality and mortality due to any other cause [27], besides being associated with poorer prognosis and quality of life [26]. Consequently, several studies recommend that these patients should be screened for depressive symptoms [26, 28, 29] and stress the possible impact of depression on adherence to treatment [28]. It would also be interesting to determine whether early intervention to treat depression alters the evolution of the illness [26, 29] and whether this strategy shortens periods of sick leave in these patients.

Acute coronary syndrome has a high economic burden. The indirect costs associated with lost productivity, which according to a previous study represents only $13 \%$ of the total cost per person [5], are estimated at 9,673.05 euros per period of sick leave. For reference, according to the National Institute of Statistics, the Spanish minimum wage during the study period was 8,400 euros in 2008 and 8,979.6 euros in 2011 [30]. The 9,673 euros represent a 115 and a $108 \%$ of the minimum interprofesional salary in spain in year 2008 and 2011 respectively. Obviously, the direct costs must also be added to the equation.

The limitations of our study are mainly to do with the data collection, due to the possible loss of some prescriptions of antidepressant or anxiolytic medication supplied without a Social Security prescription orthrough other subsidized health insurance systems in Spain such as ISFAS and MUFACE. However we believe that the patients not covered by Social Security represent only a small proportion of the total and do not create a selection bias. We should also bear in mind that this is a descriptive study of the duration of sick leave for IHD which did not have access to other data that might influence the condition - for instance, cardiovascular or socioeconomic risk factors, or other prognostic risk factors associated with the disease such as inclusion in a rehabilitation program. On the other hand we are unable to include information on the severity of the event, which would have been very interesting. The patient's type of employment should also be considered, in terms of the physical exertion required and the degree of associated stress. We would also like to have references from other diseases. Future studies should compare the economic impact of sick leave due to different pathologies using the same methodology (i.e., the same follow-up, the same context, and so on). These and other factors, in addition to the calculation of the total cost per patient (direct and indirect), should be included in future studies.

\section{Conclusions}

Patients on sick leave due to ischemic heart disease spend an average of almost six months off work, a considerably longer period than that recommended by the Spanish Social Security system. This means that the 
indirect health costs of acute coronary syndrome are particularly high. Patients are mostly men, and the most frequent diagnosis is AMI. After the event, patients' consumption of medication doubles, with over a third receiving anxiolytics and 15\% antidepressants. The factors associated with a longer duration of incapacity are older age, acute myocardial infarction and receiving antidepressant treatment.

\section{Abbreviations}

ACS: Acute coronary syndrome; AMl: Acute myocardial infarction; IHD: Ischemic heart disease; INSS: Spanish national social security institute; SD: Standard deviations

\section{Acknowledgements}

The authors thank Miquel Buti for his role in the management of data base from clinical records; USR-Lleida for the help with the data analisis; Jordi Gol Primary Care Research Foundation for funding the translation of this study.

\section{Funding}

There was no external source of funding for this study.

\section{Availability of data and material}

Due to data protection law, and that we do not have authorization from our institution (ICS), we cannot share data on open character. We have no problem sharing data and statistical code to anyone who expresses a desire to replicate the study, and/or collaborate on secondary analysis. Requests for access to data, statistical code, and technical processes may be made by contacting the corresponding author at ncatala@hotmail.com

\section{Authors' contributions}

NC and CS researched data, contributed to the discussion, and wrote the manuscript. JR researched data, contributed to the discussion, and edited the manuscript. OY and LG researched data. All authors read and approved the final manuscript.

\section{Competing interests}

The authors declare that they have no competing interests.

\section{Consent for publication}

Not applicable.

\section{Ethics approval and consent to participate}

The study protocol was approved by Clinical Ethics Committee of the Primary Healthcare University Research Institute IDIAP-Jordi Gol (P14/081). The study was based on computerized medical records retrospectively and these were treated anonymously, with no possibility to indentify patient. For this reason, informed consent wasn't obtained. No children under 16 years old were involved in the study.

\section{Author details}

'ABS Eixample, Institut Català de la Salut, Balmes avenue, 4, 25006 Lleida, Spain. ${ }^{2}$ Institut Universitari d'Investigació en Atenció Primària Jordi Gol (IDIAP Jordi Gol), Lleida, Spain. ${ }^{3}$ Facultat de Medicina i Ciències de la Salut, Universitat Internacional de Catalunya, Sant Cugat, Barcelona, Spain. ${ }^{4}$ Servicio de Urgencias del Hospital Universitari Arnau de Vilanova, Lleida, Spain. ${ }^{5}$ Departament Català de la Salut, Servicio de farmacia, Lleida, Spain.

Received: 4 June 2016 Accepted: 23 December 2016

Published online: 18 January 2017

\section{References}

1. Baena JM, del Val JL, Tomàs J, Martínez JL, Martín R, González I, et al. Epidemiología de las enfermedades cardiovasculares y factores de riesgo en atención primaria. Rev Esp Cardiol. 2005;58:367-73.

2. López J, Rodríquez A, Fernández S. Cardiopatía isquémica. AMF: Actualización en Medicina de Familia. 2011;7(6):304-15.
3. Nichols M, Townsend N, Scarborough P, Rayneret M. European cardiovascular disease statistics 2012. Sophia antipolis: European Heart Network, Brussels, European Society of Cardiology, Sophia Antipolis; 2012:104.

4. Fernández J, López SE. Carga económica y social de la enfermedad coronaria. Rev Esp Cardiol Supl. 2013;13(B):42-7.

5. Sicras A, Fernández J, Navarro R, Martín I, Varela C. Morbimortalidad y consumo de recursos asociados tras síndrome coronario agudo en una población española. Revista clínica española. 2011;211(11):560-71.

6. Oliva J, Lobo F, López J, Duque B, Osuna R. Costes no sanitarios ocasionados por las enfermedades isquémicas del corazón en España. 2004. España: Ministerio de Industria, Comercio y Turismo.

7. Carrera T, Puente E. Cardiopatía Isquémica: Protocolo de estudio en contingencia profesional en Andalucía. http://www.instituto-de-cienciasforenses.com/app/download/9527389/MME+2011++CARDIOPATIA +ISQUEMICA++word+def.pdf. Accessed 22 Dec 2016.

8. Jiménez M, Mata C, Bascuas J, Abad E, García Al, E. Reincorporación labora del trabajador coronario: criterios objetivos para un cambio de puesto de trabajo. Trauma. 2008;19(3):165-70.

9. Gutiérrez J, Vacas M, Lobato A, Llorca J, Prieto JA, Domenech J, et al. Impacto del infarto de miocardio en la situación laboral de los pacientes. Rev Esp Cardiol. 1999:52:556-62.

10. Tiempos estándar de Incapacidad Temporal. España: Instituto Nacional de la Seguridad Social. 2a edición. http://www.abc.es/gestordocumental/uploads/ economia/Tiempos\%20estandar\%20incapacidad\%20temporal.pdf. Accessed at 20/03/15

11. Perk J, Alexanderson K. Sick leave due to coronary artery disease or stroke. Scand J Public Health. 2004;32(63 suppl):181-206.

12. WHO Collaborating Centre for Drug Statistics Methodology. 2010. http://www.whocc.no/atc_ddd_index/. Accessed 22 Dec 2016.

13. Ferreira I. Epidemiología de la enfermedad coronaria. Rev EspCardiol. 2014; 67(2):139-44.

14. Go AS, Mozaffarian D, Roger VL, Benjamin EJ, Berry JD, Borden WB, et al. Executive summary: heart disease and stroke statistics-2013 update: a report from the American Heart Association. Circulation. 2013; 127:143-52

15. Ministerio de Sanidad, Servicios Sociales e Igualdad. Población con alguna enfermedad o problema de salud crónicos percibido según sexo y grupo de edad. Encuesta Nacional de Salud del Instituto Nacional de Estadística (INE) 2011-2012 [citado 30 Sep 2013]. http://www.ine.es/jaxi/tabla. do? path $=/$ t15/p419/a2011/p04/I0/\&file=04008.px\&type $=$ pcaxis\&L $=0$ Accessed at 20/03/15

16. Lerner D, Kannel W. Patterns of coronary heart disease morbidity and mortality in the sexes: a 26-year follow-up of the Framingham population. Am Heart J. 1986;111:383-90

17. Gordon T, Kannel WB, Hjortland MC, MCNamara PM. Menopause and coronary heart disease. The Framingham Study. Ann Intern Med. 1978;89:157-61.

18. Andrée M, Duran X, Alonso J, Martínez JM, Espallargues M, Benavides FG. Estimación de la carga de enfermedad por incapacidad laboral permanente en España durante el período 2009-2012. Rev Esp Salud Pública. 2014;88: 349-58.

19. Janzon M, Levin LA, Swahn E. Cost-effectiveness of an invasive strategy in unstable coronary artery disease: results from the FRISC II invasive trial. The Fast Revascularisation during InStability in Coronary artery disease. Eur Heart J. 2002;23(1):31-40.

20. Shanfield SB. Return to work after an acute myocardial infarction: a review. Heart Lung. 1990;19(2):109-17.

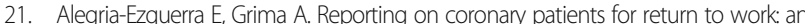
algorithm. e-journal of the ESC Council for Cardiology Practice. 2012; 10(20-23).

22. Mittag O, Schramm S, Böhmen S, Hüppe A, Meyer T, Raspe H. Medium-term effects of cardiac rehabilitation in Germany: systematic review and meta analysis of results from national and international trials. Eur J Cardiovasc Prev Rehabil. 2011:18:587-93.

23. Mirmohammadi SJ, Sadr-Bafghi SM, Mehrparvar AH, Gharavi M, Davari MH Bahaloo $M$, et al. Evaluation of the return to work and its duration after myocardial infarction. ARYA Atheroscler. 2014;10(3):137.

24. Boudrez H, De Backer G. Recent findings on return to work after an acute myocardial infarction or coronary artery bypass grafting. Acta Cardiol. 2000; 55:341-9.

25. Levine GN, Bates ER, Blankenship JC, Bailey SR, Bittl JA, Cercek B, et al. 2011 ACCF/AHA/SCAI Guideline for percutaneous coronary intervention. A report of the American College of Cardiology Foundation/American Heart Association 
Task Force on Practice Guidelines and the Society for Cardiovascular Angiography and Interventions. J Am Coll Cardiol. 2011;58:44-122.

26. Kronish IM, Krupka DJ, Davidson KW. How should we treat depression in patients with cardiovascular disease? Dialogues Cardiovasc Med. 2012;17(2):126-33

27. Nabi H, Shipley MJ, Vahtera J, Hall M, Korkeila J, Marmot MG, Kivimäki M, et al. Effects of depressive symptoms and coronary heart disease and their interactive associations on mortality in middle-aged adults: the Whitehall II cohort study. Heart. 2010;96(20):1645-50.

28. Lichtman JH, Bigger JT, Blumenthal JA, Frasure-Smith N, Kaufmann PG, Lespérance $F$, et al. Depression and coronary heart disease recommendations for screening, referral, and treatment: a science advisory from the American Heart Association Prevention Committee of the Council on Cardiovascular Nursing, Council on Clinical Cardiology, Council on Epidemiology and Prevention, and Interdisciplinary Council on Quality of Care and Outcomes Research: endorsed by the American Psychiatric Association. Circulation. 2008;118(17):1768-75.

29. Pozuelo L, Tesar G, Zhang J, Penn M, Franco K, Jiang W. Depression and heart disease: what do we know, and where are we headed? Cleve Clin J Med. 2009, 76(1):59-70.

30. Salario mínimo interprofesional (SMI). Instituto Nacional de Estadística (INE): http://ine.es/ss/Satellite?c=INESeccion_C\&param3=1259924822888\&p=1254 735110672\&pagename=ProductosYServicios\%2FPYSLayout\&cid=12599 $31351611 \& \mathrm{~L}=0$ Accesset at 6/10/2016

\section{Submit your next manuscript to BioMed Central} and we will help you at every step:

- We accept pre-submission inquiries

- Our selector tool helps you to find the most relevant journal

- We provide round the clock customer support

- Convenient online submission

- Thorough peer review

- Inclusion in PubMed and all major indexing services

- Maximum visibility for your research

Submit your manuscript at www.biomedcentral.com/submit 